Artigos

\title{
Educação e esfera pública democrática Um capítulo negligenciado da filosofia política
}

\author{
Education and democratic public sphere
} A neglected chapter of the political philosophy

Axel Honneth*

\begin{abstract}
Resumo: O texto discute a relação entre a educação e a organização democrática do governo republicano. Para o autor, pelo menos desde Kant os teóricos clássicos da filosofia política estavam convencidos de que uma boa educação e uma ordem estatal republicana dependem uma da outra: formar cidadãos para a liberdade para que, como cidadãos autônomos institucionalizem uma educação pública que possibilite a seus filhos o caminho para a maioridade política. Mas ele constata hoje um divórcio entre as gêmeas teorias da democracia e da educação. Razões que podem ter levado a essa cisão ele localiza na combinação, por afinidades eletivas, entre uma concepção truncada de democracia, que dependeria de comunidades tradicionais e mesmo religiosas para reproduzir suas bases ético-culturais, e uma falsa concepção normativa de neutralidade do estado, que culmina concebendo os professores não mais como servidores públicos a serviço do estado democrático de direito, mas como servidores dos pais. Em contraposição ao desacoplamento entre a formação do cidadão autônomo e do governo autônomo dos cidadãos, entre pedagogia e teoria política, ele reconstrói, a partir dos clássicos da teoria social, a concepção sobre um nexo fundamental entre educação e liberdade política, entre formação e democracia. Longe de advogar por uma volta à escola tradicional, o autor chama a atenção para dois grandes desafios que juntas, pedagogia e teoria democrática precisam enfrentar: o impacto da revolução digital sobre a esfera pública e a crescente heterogeneidade cultural dos cidadãos, em especial nas democracias ocidentais, para que a educação torne a ser o lugar do aprendizado da cultura democrática. (Resumo do editor).
\end{abstract}

Palavras-chave: Educação pública. Esfera pública. Teoria política. Pedagogia. Cidadania.

* Doutor e livre-docente em Filosofia, professor na Universidade de Frankfurt (Alemanha) e diretor do Instituto para Pesquisa Social. Principais publicações: Luta por reconhecimento (Editora 34), Verdinglichung (Suhrkamp), Sofrimento de indeterminação (Esfera Pública), Das Recht der Freiheit (Suhrkamp). Conferência de abertura do $23^{\circ}$ Congresso da Sociedade Alemã de Educação (DgfE - 12 mar. 2012, em Osnabrück), gentilmente cedida pelo autor para publicação na Civitas < honneth@em.uni-frankfurt.de>. Tradução do alemão, com apoio do CNPq (edital 15/2011): Luis Marcos Sander.

\begin{tabular}{|l|l|l|l|l|l|}
\hline Civitas & Porto Alegre & v. 13 & n. 3 & p. 544-562 & set.-dez. 2013 \\
\hline
\end{tabular}




\begin{abstract}
The text discusses the relationship between education and democratic organization of the republican government. For the author, at least since Kant's political philosophy classical theorists were convinced that a good education and a republican state order depend from and are complementary to one another. to educate citizens for freedom so that, as autonomous citizens, they can institutionalize a public education that enables their children to find the way for the political majority. But today we can see a divorce between the twin theories of democracy and education. Reasons that may have led to this split he finds in the combination, by elective affinities, between a truncated conception of democracy, which depends on traditional and even religious communities to reproduce the own ethical and cultural foundations, and a false normative conception of the neutrality of the state, conceiving teachers not as public servants serving a democratic state of law, but as parents servants. In contrast to the decoupling between the formation of the autonomous citizens and the self-government, between pedagogy and political theory, the author reconstructs the classical conception of a fundamental link between education and political freedom, between education and democracy. Far from advocating for a return to the traditional thought, the author draws attention to two major challenges pedagogy and democratic theory must confront together: the impact of the digital revolution on the public sphere and the growing cultural diversity of citizens, especially in Western democracies. Only so education can again be the place of learning democratic culture. (Editor's abstract).
\end{abstract}

Keywords: Public Education. Public sphere. Political theory. Pedagogy. Citizenship.

A história do sistema público de educação nos estados constitucionais democráticos é, desde seus primórdios no século 19, uma cadeia ininterrupta de conflitos em torno da subdivisão, da forma e do conteúdo do ensino escolar. Os confrontos travados encarniçadamente ou entre representantes de interesses de classes sociais ou os pais organizados e as autoridades estatais não deixaram intocados nem a estratificação do sistema escolar, nem os métodos de ensino, nem o currículo. A matéria explosiva contida na promessa estatal de um direito geral dos cidadãos a formação e educação talvez já tenha sido pressentida por Immanuel Kant quando, em suas preleções sobre a Pedagogia, formulou a seguinte frase famosa: "Duas invenções humanas decerto podem ser vistas como as mais difíceis, a saber, a da arte do governo e a da arte da educação, e ainda assim existe conflito até mesmo na ideia delas" (Kant, 1964, p. 703). Para Kant, o paralelo entre a arte do governo e a arte da educação resultava da consideração de que ambas são instituições criadas pela sociedade que têm de cumprir a mesma tarefa nas dimensões diferentes da história da espécie e do indivíduo, na filogênese e na ontogênese. Através de uma escolha habilidosa dos meios e métodos, ou seja, através de uma espécie de "arte", elas precisam nos ensinar como, num caso, um povo de súditos e, no outro, uma criança por natureza ainda submissa devem ser levados do estado de imaturidade para o de liberdade. 
Mas o que inicialmente parece ser apenas uma mera analogia é ampliado pelo próprio Kant muito mais vigorosamente no transcurso posterior de suas preleções quando remete à existência de uma relação de condicionamento mútuo entre ordem estatal republicana e educação: o ser humano pequeno e impelido pela natureza precisa percorrer primeiro um processo de educação voltada para a liberdade para poder se tornar membro do povo de um estado que governa a si mesmo, assim como, inversamente, só cidadãos e cidadãs autônomos podem institucionalizar uma educação pública que possibilite a seus filhos o caminho para a maioridade política. Por isso, uma boa educação e uma ordem estatal republicana dependem complementarmente uma da outra, porque a boa educação produz concretamente, por meio de uma instrução geral e pública, as capacitações culturais e morais com cuja ajuda a ordem estatal republicana pode existir e prosperar de tal maneira que a cidadania ainda participe da emancipação política também dos integrantes das classes baixas. Por conseguinte, como já no Emílio de Rousseau, na Pedagogia de Kant a ideia do "bom cidadão" (ibid., p. 760) constitui o elo de ligação entre a teoria da educação e a do governo, entre concepção de formação e filosofia política: sem uma, a outra não seria possível, porque ambas explicam pressupostos de uma coletividade democrática que não poderiam existir independentemente um do outro.

É essa vinculação extremamente estreita e interna que fez com que, no discurso político-filosófico da era moderna, quase todos os teóricos da democracia famosos tenham produzido uma contribuição sistemática para a teoria da educação; iniciando por Rousseau e Kant, passando por Schleiermacher (2000) e chegando até Emile Durkheim (1973) e John Dewey (1993), sempre houve grandes e importantes pensadores para os quais era natural dedicar uma monografia própria ao tema da educação pública. A pedagogia, entendida como a teoria dos critérios e métodos de uma instrução adequada das gerações futuras, era compreendida como irmã gêmea da teoria da democracia, porque sem orientações equilibradas sobre como se devem despertar na criança, ao mesmo tempo, a capacidade para a cooperação e a iniciativa moral própria, não parecia possível se explicar o que significaria falar da cooperação conjunta na autodeterminação democrática. A ideia do "bom cidadão" não era uma fórmula vazia ou peça decorativa de discursos políticos festivos, e sim um desafio prático, e era preciso se mostrar à altura dele através do esboço teórico e até do teste experimental de formas escolares e métodos de ensino apropriados. Por isso, quando, após o desmantelamento do nacional-socialismo, tratou-se de acostumar um povo inteiro de novo às práticas sistematicamente desaprendidas da formação democrática da vontade, as forças de ocupação americanas puderam recorrer com toda a naturalidade 
aos textos pedagógicos de seu conterrâneo John Dewey para dar conta da tarefa que tinham pela frente (cf. Gagel, 2005, cap. 2). O vínculo entre a teoria democrática e a prática pedagógica ainda era tão estreito, o nexo interno entre ambas ainda parecia dado de modo tão evidente que não havia paternalismo ou tutela no propósito de ensinar de novo costumes democráticos aos membros desmoralizados de um estado injusto arrasado e reduzido a cinzas. Desde então, porém, a vinculação de democracia e concepção educacional, de filosofia política e pedagogia está rompida. Certamente há repetidamente iniciativas de refletir sobre a necessidade de uma educação democrática, mas elas geralmente vêm de uma ciência educacional que foi deixada sozinha, e não mais do centro da própria filosofia política. A teoria da democracia, na diversidade de suas formas e vozes, silencia hoje amplamente sobre o lado educacional de seu métier; não se encontram mais nela reflexões sobre métodos escolares nem sobre o currículo. Qualquer noção de que uma democracia vital precisa primeiro gerar, através de processos de formação geral, os pressupostos de sua própria subsistência cultural e moral foi entrementes perdida pela filosofia política. Antes de, num segundo passo do texto, expor mais uma vez - retomando a tradição a que acabo de apenas aludir - o nexo entre educação e liberdade política, entre formação e democracia (2), pretendo, num primeiro passo, mencionar inicialmente as razões do desligamento entre pedagogia e filosofia política entrementes ocorrido. Essas razões residem, como se mostrará, numa união fatal, baseada no que se pode chamar de "afinidade eletiva", de concepções problemáticas a respeito dos pressupostos culturais da democracia e de um imperativo de neutralidade estatal compreendido erroneamente (1). Depois de ter defendido, dessa maneira, tanto em termos negativos quanto positivos uma reaproximação entre a teoria da educação e a da democracia, pretendo finalmente, num terceiro passo, delinear os principais desafios com que se confronta atualmente um programa renovado de educação democrática; ao fazer isso, terei de me contentar em indicar algumas palavras-chave, pois qualquer exposição mais detalhada extrapolaria os limites de tempo de minha palestra (3).

Enquanto que Kant, Durkheim ou Dewey ainda consideravam o tema da educação democrática parte integrante de seus próprios empreendimentos político-filosóficos, hoje em dia, dentro da teoria da democracia de orientação normativa, esse tema só tem ainda um papel marginal. Embora ocasionalmente ele ainda seja mencionado mais uma vez nesse âmbito e, nas respectivas introduções, seja sempre indicado de novo como um campo que faz parte de 
suas tarefas, sua exploração, definição e exposição como tal acabam sendo deixadas por conta da pedagogia científica. ${ }^{1}$ A teoria da democracia deu adeus à sua irmã gêmea, à teoria da organização e do métodos adequados de uma formação democrática e, com isso, privou-se da possibilidade de dar uma contribuição própria acerca da função normativa da pré-escola, da escola e da formação de adultos. Face a essa evolução, seria possível tranquilizar-se com a constatação de que ela apenas reflete o resultado de uma diferenciação ulterior das distintas disciplinas científicas que podemos observar há cerca de 200 anos; assim como a filosofia teve de se separar da teoria da sociedade na segunda metade do século 19, que depois pôde se estabelecer na disciplina da sociologia, ela precisou, no transcurso de sua crescente especialização, desligar-se também da tarefa de definir com recursos próprios os processos educacionais necessários para a formação da maioridade democrática. A própria circunstância de que a filosofia política se depara de novo, em todo lugar imaginável, com o problema da educação, sem dispor atualmente sequer do rudimento de uma solução, mostra que as coisas não são tão simples e, pelo contrário, remetem a um problema mais grave. Com a implementação estatal de uma frequência escolar obrigatória para todos, o ensino administrado pelas autoridades públicas se tornou uma alavanca decisiva da formação de comportamentos e capacidades da geração subsequente, de modo que ele exerce, tanto para o bem quanto para o mal, influência sobre as qualidades do futuro cidadão e da futura cidadã. O tipo de educação escolar, seus métodos e conteúdos, pode repercutir de maneira desejável na consistência de uma democracia, promovendo, por exemplo, a capacidade de cooperação e a autoestima individual, ou então contribuir, de maneira negativa, para seu insidioso solapamento quando ela veicular a submissão à autoridade e o conformismo moral. ${ }^{2}$ Neste sentido, a questão da forma adequada da educação organizada pelo estado constituiu, desde o início - pensemos apenas na Politeia de Platão (1990, v. 4, espec. livro 5º cf. Dewey, 1993, p. 122-126) - um ponto central de toda filosofia política. Quem se ocupava com a questão de como deveria ser um estado ou uma coletividade política face à natureza humana não podia nem devia se esquivar do problema conexo de quais conteúdos a educação escolar deveria ensinar a quais alunos segundo qual método. Por conseguinte, se atualmente essa questão é amplamente excluída na filosofia política e não é aprofundada nela nem em sua forma positiva nem em sua forma negativa, isso

1 Uma grande exceção é constituída pela filósofa política Amy Gutmann (1999), para a qual, entretanto, a tradição aqui mencionada só tem importância muito secundária.

2 Nesse papel "negativo" a escola aparece, por exemplo, na filosofia política de Louis Althusser (1973, espec. p. 140ss). 
não pode se dever simplesmente à eliminação racionalmente compreensível de um tema que pode ser tratado de modo muito melhor e mais adequado em outra área. O problema da educação organizada pelo estado se encontra por demais no centro de toda ação política e toca de maneira por demais abrangente os pressupostos da consistência do estado de direito democrático para que pudesse atualmente ser separada assim sem mais nem menos do corpus de uma ciência ou filosofia da política.

Portanto, as razões que podem ajudar a explicar o crescente desligamento da teoria da democracia em relação à da educação precisam ser situadas em outro nível do que aquele da progressiva diferenciação de disciplinas avulsas. Suponho que elas estejam, em vez disso, num nível conceitual, bem mais profundo, onde estão em pauta a definição e exploração da abrangência em que a democracia pode influir sobre si mesma. Como regra geral teórica podese afirmar, neste caso, que essa abrangência deve ser vista como tanto menor quanto mais partes dos pressupostos de sua própria consistência parecem estar subtraídas do estado democrático de direito, seja por causa de restrições normativas, seja de indisponibilidades materiais; e poder-se-ia dizer que se, por fim, essa margem para atividades autogeradoras só for considerada extremamente pequena, então, por consequência, dificilmente ainda se poderá atribuir uma importância política à educação escolar, porque mesmo com sua ajuda as condições de vida da democracia não podem ser transformadas. Em minha opinião, são mudanças teóricas dessa espécie, portanto desilusões quanto às forças autogeradoras de coletividades democráticas, que são substancialmente responsáveis pelo fato de que a filosofia política só dá ainda pouca atenção à educação organizada pelo estado. Gostaria de mencionar duas das fontes teóricas que, ao longo das últimas décadas, fizeram com que a teoria da democracia perdesse, quase imperceptivelmente e por trás de suas costas, a crença no valor da educação organizada pelo estado para a democracia. Certamente seria possível mencionar ainda categorias de influência de outra espécie, por exemplo o deslocamento da formação do caráter para a fase da socialização na primeira infância que se subtrai ao estado, mas pretendo me limitar aos dois aspectos seguintes porque se enquadram no território da própria filosofia política.

Por um lado, para a disseminação da noção de que só resta ao estado democrático de direito uma margem muito pequena na regeneração de suas próprias condições morais e culturais pode ter contribuído a concepção tese de Böckenförde, que recebeu seu nome de seu autor - segundo a qual a democracia depende, em sua reprodução, do fornecimento de componentes de tradição anteriores a ela. Embora originalmente o especialista em direito 
público Böckenförde (2006, p. 42-57) decerto tenha compreendido sua percepção em termos muito mais restritos, a saber, como referência aos pressupostos da consistência moral apenas do direito moderno, entrementes ela é interpretada de maneira muito mais ampla e tida como comprovante da falta de independência cultural de todos os estados democráticos de direito; segundo essa versão generalizada, tais sistemas políticos dependem constantemente de encontrarem, através de costumes e comportamentos morais, um apoio cultural para cujo crescimento e cultivo eles próprios não possuem os instrumentos apropriados. No mais elevado nível de generalização, a chamada tese de Böckenförde afirma, hoje em dia, inclusive que as democracias devem sua conservação social a atitudes morais que só podem prosperar em comunidades consolidadas com orientações éticas substanciais e até religiosas. Mas se se toma uma noção dessas como ponto de partida, torna-se plausível tirar a conclusão de que se deve negar aos processos educacionais organizados pelo estado, portanto à formação escolar e pré-escolar, qualquer valor para a transmissão de comportamentos promotores da democracia, pois o que, em termos de atitudes morais, vem ao encontro da formação da vontade de cooperação - capacidade de tolerância, poder se colocar no lugar dos outros, orientação pelo bem comum - não é aprendido em processos de ensino, por melhor que sejam conduzidos, mas somente no ambiente de socialização ética de comunidades pré-políticas. Enquanto que em Böckenförde (ibid., p. 48) ainda se encontram ao menos indicações de que a "formação e educação" podem realizar essa obra, na recepção geral de sua tese resta apenas a convicção da necessidade de as sociedades democráticas confiarem na sobrevivência de comunidades tradicionais formadas em torno de atitudes mentais: todos os esforços estatais de organização de uma educação democrática são em vão porque não podem gerar as virtudes morais que são vitalmente necessárias para a subsistência de democracias.

Com a penetração dessa concepção no conjunto teórico da filosofia política decerto está mencionado um dos pressupostos que fez com que na mais recente teoria da democracia se mantivessem em grande parte afastadas questões referentes à educação pública; tais problemas precisam mostrarse supérfluos na medida em que parece estar estabelecido que atitudes democráticas não são adquiridas em processos educacionais mediados pelo estado, mas nos ambientes pré-políticos de comunidades tradicionais. A versão popular da tese de Böckenförde, porém, não constitui a única razão que faz com que atualmente a teoria da democracia se distancie cada vez mais de sua ex-irmã gêmea, a teoria da educação. A partir de um outro lado, mais fortemente normativo, vem ainda ao encontro de tais tendências de 
desligamento a propensão a interpretar o imperativo da neutralidade do estado de modo tão restritivo que até mesmo os princípios da formação da vontade democrática não podem mais se expressar de modo algum no ensino escolar público.

Como já a reinterpretação neoconservadora da democracia, segundo a qual esta última só permanece viável mediante um fornecimento permanente de componentes de tradições anteriores a ela, a exacerbação do imperativo da neutralidade do estado ocorreu mais às costas da filosofia política do que de maneira deliberada e plenamente consciente; pode até ser que esse segundo deslocamento teórico seja a consequência involuntária da intenção, de modo geral boa, de levar em consideração o crescente pluralismo de culturas étnicas e religiosas em nossas sociedades através de uma acentuação da imparcialidade estrita do ensino organizado pelo estado. Naturalmente a definição política do grau de neutralidade estatal está sujeita desde sempre a um fluxo constante em que se refletem, de maneira quase intransparente, as convicções éticas de uma maioria e, com isso, também a situação das forças sociais; a legitimidade de tais vinculações valorativas só se mede, em última análise, pelo critério de elas não violarem os princípios universalistas de constituições democráticas. Na disputa perpétua em torno da inevitável parcialidade da ação estatal, nunca havia dúvida, para a tradição acima mencionada por mim, que se estende de Kant até Durkheim e Dewey, de que o ensino promovido pelo estado deve corporificar exatamente os valores que se expressaram na decisão de torná-lo obrigatório para todos os futuros cidadãos: o direito dos pais de transmitir a seus filhos suas próprias convicções valorativas particulares tinha de ser rompido no portão da escola para se poder abrir aos pupilos o caminho para participar da formação da vontade pública mediante o exercício de comportamentos reflexivos. Mas a naturalidade que se expressa em tal direcionamento do ensino escolar para os mesmos procedimentos democráticos pelos quais ele próprio foi criado como obrigatório para todos está sendo questionada em grau crescente hoje em dia. Ao fazer isso, ou se apela para o imperativo da neutralidade do estado para advertir contra uma sobrecarga da educação escolar com valores políticos, estranhos a ela, ou se reclama, por parte de pais interessados, que com uma orientação excessivamente forte por objetivos democráticos a transmissão de funções promotoras da carreira profissional poderia ficar prejudicada. Se tais reservas antigas ainda recebem, involuntariamente, apoio público pelo fato de que, face ao multiculturalismo consolidado, de fato muita coisa depõe em favor de uma libertação de nossas escolas de resíduos cosmovisivos, então surge imperceptivelmente aquela mescla difusa de coisas erradas e certas a partir da qual, de repente, toda e qualquer espécie de parcialidade do ensino 
escolar tem de ser considerada igualmente problemática ou condenável; por consequência, o imperativo da neutralidade do estado é estendido até o ponto em que a própria ideia da educação democrática perde sua naturalidade normativa.

Certamente a filosofia política da atualidade ainda não está, em seu conjunto, permeada por tais interpretações radicalizadas do imperativo da neutralidade da ação estatal; nela se continua, pelo contrário, discutindo com veemência sobre como essa peça herdada do pensamento liberal sobre o estado poderia ser adequadamente reformulada face à crescente heterogeneidade de noções culturais de valores (cf. Rawls, 1992, p. 364-397; Forst, 1994, p. 78-83). Ainda assim, em conexão com as reinterpretações culturais conservadoras da viabilidade das democracias se delineia atualmente uma evolução teórica em cujo fim poderá se encontrar a convicção de que os métodos e conteúdos do ensino administrado pelo estado também precisam ser libertados de todos os objetivos democráticos. Em correspondência com tal ponto de fuga concebível já se encontram hoje em dia ponderações no sentido de só incumbir a escola ainda com a tarefa da inculcação de um "mínimo civil" (cf. Gutmann, 1999, p. 292-303), deixar por conta dos pais, através de vales educacionais (ibid., p. 65-66; Walzer, 1992, p. 314-318), a escolha do caráter cosmovisivo do ensino escolar e, de modo geral, não entender mais os professores e professoras em seu conjunto como incumbidos pelo estado de direito, mas apenas pelas associações de pais. ${ }^{3}$ Mas quanto mais longe forem levadas essas reflexões inicialmente só tentativas, quanto mais decisivamente, portanto, a escola pública fosse concebida como eticamente neutra, para colocar no lugar dela um sem-número de escola privadas com vínculo cosmovisivo, tanto mais acentuadamente a sociedade democrática perderia o quase único instrumento de que ela dispõe para a regeneração de seus próprios fundamentos morais. Neste sentido, o conflito em torno do sistema escolar estatal, independentemente de ele dizer respeito à sua estruturação, aos currículos ou aos métodos empregados, sempre é também uma luta pela viabilidade das democracias para o futuro. Em nenhuma outra tradição a consciência desse nexo esteve mais claramente presente do que naquela que foi, inicialmente, impulsionada por Kant e, por fim, encontrou seu ápice em Durkheim e Dewey.

3 Quanto a tais tendências, cf. as observações muito boas de François Dubet (2002, espec. p. 101-104). A ideia de que as professoras e os professores devem se entender como incumbidos pelo estado de direito democrático, e justamente não como agentes dos pais numa fase adiantada da vida de seus filhos, é de Emile Durkheim (1973, p. 187-198); quanto a essa problemática, cf. também Gutmann (1999, p. 292-303). 
As reflexões apresentadas até agora já mostraram indiretamente, na forma apenas negativa de uma crítica a tendências da teoria contemporânea da democracia, que premissas têm de ser pressupostas para que o sistema escolar público seja entendido como um complemento necessário e até como a outra metade da formação da vontade democrática anteposta a esta. Vimos que então não se deve abandonar a hipótese orientadora da prática de que é possível despertar educacionalmente as capacidades para a deliberação pública também para além da socialização que ocorre na primeira infância e à parte de moralidades apoiadas em tradições, e tampouco se pode colocar levianamente em jogo o direito do estado constitucional de dotar de objetivos de formação democrática os processos educacionais por ele organizados. Se essas duas premissas negativas são formuladas em termos positivos, também se pode dizer que, entre as tarefas do estado democrático de direito, deve estar em primeiro lugar a tarefa de dar a cada um de seus futuros membros de igual maneira, através de instituições de formação adequadas, a possibilidade de participar da legitimação pública de suas próprias decisões "sem medo nem vergonha". No escrito sobre a educação de Kant, que se encontra sob a forte influência do Emílio de Rousseau, ainda que sem segui-lo em tudo, a ideia assim esboçada assume provisoriamente, contra a educação "doméstica", apenas a forma de uma defesa da educação "pública", universalmente acessível, que teria a vantagem de, sem o perigo de dar continuidade a "erros de família", produzir em cada pupilo as virtudes e capacidades do "futuro cidadão". ${ }^{4}$ É interessante que tudo que deve ser transmitido pedagogicamente em tais processos educacionais - em primeiro lugar habilidades mecânicas, em segundo, prudências pragmáticas e, em terceiro, autodeterminação moral - está sujeito, para Kant (1964, p. 713), ao alvo primordial de fazer surgir no indivíduo igualmente tantas camadas de autoestima e autovalorização quantas, em conjunto, permitam-lhe atuar então de modo autoconfiante como cidadão de uma república. A pergunta a respeito da contribuição que as três classes de capacidades inculcáveis devem prestar mais tarde para o exercício da profissão nem sequer se coloca nesse contexto, pois todas são

4 Kant (1964, p. 710-712). Encontramos uma afirmação quase igual em Schleiermacher (2000, v. 1, p. 272): "Encontramos épocas na história de nosso novo mundo onde povos só parecem despertar de uma longa apatia e rudeza pelo fato de seu governo tomar para si as rédeas dessa importante atividade e procurar fazer surgir através de outros meios na geração mais jovem as forças superiores desejadas que a geração mais velha não consegue despertar por meio da educação doméstica porque elas não estão presentes ou se extinguiram nela própria”. 
vistas de igual modo sob o único ponto de vista da aquisição de diversas formas do sentimento de autoestima. Antecipando uma ideia famosa de John Rawls (1979, p. 479-486), Kant afirma que o futuro cidadão deve poder dispor primeiramente do bem central da "autoestima", antes de poder participar como igual entre iguais da autolegislação republicana. Por conseguinte, aptidões profissionais, conhecimento para se orientar na sociedade civil e princípios morais justamente não são compreendidos de maneira primordial como recursos passíveis de aprendizado para assegurar renda no futuro, mas como meios de reconhecimento social universalizados pela sociedade, e através de sua apropriação mediada pela pedagogia o jovem deve chegar paulatinamente à consciência de ter um "valor" aos olhos das demais pessoas. A obtenção de habilidades the concede, como o formula Kant (1964, p. 713) quase usando palavras de Hegel, respeito "com vistas a ele mesmo como indivíduo", a aquisição de conhecimentos sobre a sociedade civil, o "valor público" de um cidadão, e a apropriação dos princípios morais, por fim, o respeito "com vistas a toda a espécie humana".

Não obstante toda a lucidez referente ao nexo entre formação escolar geral e reconhecimento recíproco na coletividade republicana, Kant está muito distante de já tirar disso conclusões com vistas ao método e à forma organizacional do ensino escolar; ele tem em vista o pupilo individual, do sexo masculino, que deve, cada um por si, chegar à autoestima através da aquisição de conhecimento imposta pela educação, mas não a comunidade cooperativa em que cada um deve, como membro reconhecido, poder cooperar com todos os outros para a formação da vontade comum. Embora em sua Pedagogia ele já pressinta ocasionalmente que a república dependeria muito mais fortemente do ensino das virtudes comunicacionais do que da transmissão unilateral de conhecimentos, ${ }^{5}$ ainda recua diante da consequência de identificar na escola pública, primeiramente e antes de mais nada, um local de formação de capacidades democráticas. Esse passo só foi dado cerca de 100 anos mais tarde por Emile Durkheim e John Dewey, quando cada um se pôs, em sua respectiva obra, a delinear o nexo interno existente entre educação e democracia, processos de aprendizado escolar e futuro papel de cidadão.

Embora as suposições básicas dos dois pensadores pareçam quase se excluir - num caso temos o sociólogo de postura cientística e, no outro, o filósofo que procede pragmaticamente -, suas reflexões sobre a educação democrática apresentam, ainda assim, uma série de surpreendentes aspectos

5 Em Kant, essas capacidades democráticas se chamam "atitudes mentais cosmopolitas" e só aparecem ocasionalmente em sua Pedagogia (p. ex., 1964, p. 761). 
comuns. Entre as três funções que a escola deve juntar do ponto de vista atual, a da qualificação profissional, a da compensação de déficits formacionais relacionados à família ou ao ambiente e a da preparação geral para o papel de cidadão, Durkheim e Dewey visam unicamente a terceira, mencionada por último. Como já o fizera Kant, eles entendem o aprendizado de conhecimentos profissionalmente úteis mais como um resultado acidental do exercício de costumes democráticos, e tudo que deve ser oferecido em termos de educação compensatória é compreendido como tarefa evidente da respectiva comunidade escolar. Também o direito do estado democrático de vincular o sistema educacional por ele financiado por meio da cobrança de tributos à regeneração de capacidades cidadãs é fundamento por ambos os pensadores, na medida em que chegam a considerar isso necessário, com argumentos semelhantes. Como a introdução estatal da frequência escolar obrigatória só pode ser interpretada como um ato democraticamente passível de legitimação sob a condição de que ela seja avaliada como um esforço conjunto, por assim dizer da sociedade civil, de ajudar todos os cidadãos e cidadãs de igual maneira a exercer de fato seus direitos políticos, não se pode, a posteriori, negar a esse estado o direito de também utilizar efetivamente o ensino escolar para o exercício dos respectivos conhecimentos e práticas. ${ }^{6}$

Mas essas reflexões sobre a teoria da democracia constituem apenas o marco geral em que Durkheim e Dewey situam as investigações que dedicam ao teor e à estrutura do ensino escolar. $\mathrm{O}$ ponto de partida de suas reflexões, mais uma vez acentuadamente concordes, é constituída pela tese de que a preparação para o futuro papel de cidadão tem a ver menos com a transmissão adequada de conhecimentos do que com a formação de hábitos práticos. $\mathrm{O}$ que os alunos e alunas devem aprender no ensino escolar para, mais tarde, poder participar efetivamente da formação da vontade democrática não são primordialmente conhecimentos verificáveis sobre nexos políticos ou históricos, e sim condutas que permitam a atuação moralmente autoconfiante numa comunidade cooperante. Talvez não surpreenda muito que Dewey, como pragmatista, volte suas reflexões nessa direção e, portanto, compreenda a escola antes de mais nada como local de formação da cooperação na esfera pública que se dedica à pesquisa; ${ }^{7}$ mas o fato de que Emile Durkheim argumenta de modo semelhante e também observa a escola sob o ponto de vista de sua contribuição para o exercício de capacidades de cooperação democrática decerto necessita de uma breve explicação.

\footnotetext{
Quanto a esses argumentos, cf. também Gutmann (1999, cap. 2).

7 Quanto à pedagogia de Dewey de modo geral, cf. Jürgen Oelkers (2009).
} 
Inicialmente, Durkheim - diferentemente de Dewey, que pensava de maneira bem mais otimista neste tocante - se orienta pela noção inspirada em Kant de que em cada criança as propensões egoístas precisam ser primeiro quebradas por disciplinamento moral, antes de ela aprender a se ater autonomamente às regras sociais da comunidade democrática. Entretanto, ele se afasta consideravelmente de seu mestre filosófico na medida em que vê esse processo educacional anteposto ocorrendo de maneira tanto mais flexível e, sobretudo, mais auspiciosa quanto mais fortemente se envolverem nele, através de exemplos práticos e atividades lúdicas, também as paixões e os desejos, em suma, a natureza sensorial da criança (Durkheim, 1973, p. 158-159). A rigor, portanto, o rompimento do egoísmo infantil justamente não representa para Durkheim - embora ele fale disso repetidamente - um processo de disciplinamento moral, e sim de formação de hábitos mediada por afetos: participando de práticas que lhe sejam adequadas, ou seja, que afetem suas propensões, a criança aprende inicialmente apenas a dominar habitualmente as regras da convivência democrática que mais tarde, à medida que for ficando mais velha, deverá compreender também em termos da pretensão de validez racional que elas levantam. Mas, a partir dessas correções de Kant, Durkheim consegue tirar quase as mesmas consequências para a escola e seus estilos educacionais às quais Dewey tinha chegado partindo de premissas inteiramente diferentes, a saber, hegelianas: no ensino escolar, as novas gerações precisam ser habituadas, através de métodos de aprendizado tão cooperativos quanto possível, através de cogestão em todos os assuntos que digam respeito à escola e, por fim, através de formas mais comunitárias do que individuais de censura e incentivo, a se apropriar, já cedo, daquele espírito de cooperação democrática que mais tarde, na idade adulta, pode ajudá-las a atuar de maneira autoconfiante na esfera pública política. Neste sentido, os dois pensadores não são da opinião, atualmente defendida com frequência, de que a escola deve servir primordialmente à formação da autonomia individual; a imagem de educação deles se caracteriza, pelo contrário, de modo consentâneo, pela ideia de ensinar aos alunos uma percepção certeira do que significa entender o colega como um parceiro com direitos iguais num processo comum de aprendizado e investigação. Para que a escola pública volte a gerar em cada nova geração as formas de comportamento que são vitalmente necessárias para a formação da vontade democrática, ela deve apostar muito mais fortemente na habituação a uma cultura associativa do que na transmissão unilateral de princípios morais. ${ }^{8}$

8 Quanto à defesa dessa ideia de uma "moral da associação" como orientação para a escola, cf. também Gutmann (1999, p. 59-64). 
Para Durkheim e Dewey, não é o aprendizado de princípios individuais da ação correta, mas o exercício comunicacional da adoção de perspectivas e a iniciativa moral que constituem a via régia na qual o ensino escolar pode contribuir para a regeneração da democracia.

Contudo, não só entre a pedagogia de Kant e essas formulações já se passou um século, mas também entre elas e nosso presente passou mais uma vez o mesmo número de anos. Por isso, face à grande distância temporal, muitos talvez abanem a cabeça e indiquem, com um gesto triunfalista, que entrementes, junto com o entorno social e econômico, as exigências feitas à escola também mudaram radicalmente: os números de alunos que aumentaram enormemente, a expectativa de flexibilidade e disposição para o desempenho que tem a economia, os déficits educacionais das camadas inferiores que persistem inalterados apesar de todos os esforços sociopolíticos, tudo isso parece, nos países capitalistas altamente desenvolvidos, não deixar ao ensino escolar outra opção do que apostar de modo mais acentuado na pressão seletiva, no controle do desempenho individual e no estímulo ao comportamento concorrencial (cf. por exemplo Dubet (2002, cap. 3; 2000). Nos Estados Unidos, políticos, especialistas em economia e gerentes já estão propondo uma reforma da totalidade do sistema escolar que, somando-se às medidas anunciadas, resumir-se-ia a uma ativação do ensino em favor da aquisição de capacidades aproveitáveis do ponto de vista puramente econômico: segundo esses planos, a efetividade de todas as escolas americanas seria controlada comparativamente com base em dados quantitativos, que medem o sucesso de cada professor e professora de acordo com o resultado que ajudou seus alunos a atingir em testes padronizados em nível nacional (Ravitch, 2012). Processos de controle dessa espécie, que teriam como consequência, no curto ou longo prazo, a marginalização de todas as disciplinas estatisticamente não verificáveis, estão sendo, entrementes, discutidos não só nos EUA, mas também no continente europeu, como se, também aqui, se devessem submeter as escolas, com a ajuda de métodos da economia financeira, unilateralmente aos ditames do desenvolvimento econômico. Sob tais circunstâncias, parece não haver necessidade de recordar os tempos em que o ensino escolar público era visto como elemento fulcral da autorrenovação das democracias. Ao que tudo indica, não só a própria teoria da democracia, mas também a política estatal perderam o interesse pelo único órgão com o qual se podiam regenerar repetidamente, ao menos tentativamente e num esforço constante, os frágeis pressupostos de uma formação da vontade democrática do povo.

Entretanto, todos os levantamentos empíricos que a pesquisa comparada da formação e os diversos estudos do Pisa revelaram nos últimos 
anos contradizem essas tendências a um afastamento da ideia da educação democrática, pois neles se confirma, de maneira quase admirável, o que Durkheim e Dewey tinham previsto há um século, quando quiseram estabelecer uma relação bem estreita entre métodos de ensino cooperativos e promotores da democracia e o desempenho escolar. Ocorre que o sistema escolar que, em todas as comparações de desempenho em nível internacional, alcança os melhores resultados é, ao mesmo tempo, aquele em que os ideais democráticos desses dois pensadores ainda foram melhor realizados: nas escolas finlandesas, os alunos de origens formacionais diferentes permanecem juntos tanto tempo quanto possível numa única comunidade escolar, os processos de testes e exames são reduzidos ao mínimo necessário, atribui-se à responsabilidade comunicacional e à confiança mútua mais importância do que à imputabilidade individual e, por fim, a soberania sobre a moldagem do ensino pertence unicamente a um quadro de professores com formação profissional que coopera estreitamente com os representantes dos alunos (Sahlberg, 2012). Certamente, nas descrições do sistema escolar na Finlândia não é utilizado o vocabulário de Durkheim e Dewey, pois aí não se fala de formação de hábitos nem de moral comunitária ou métodos cooperativos de educação. Mas essas traduções para uma linguagem de formação democrática parecem ser facilmente possíveis e manifestariam, então, o feliz acaso, raro e historicamente improvável, de que o política e normativamente correto coincidiria, uma vez, com o pragmaticamente adequado: as melhores formas escolares para as realizações e capacidades cognitivas dos alunos são aquelas que, ao mesmo tempo, vêm mais acentuadamente ao encontro da regeneração de condutas democráticas. Por conseguinte, em tempos nos quais se fala em toda parte da existência de uma apatia política crescente e até se aponta para o perigo de uma "pós-democracia" (Crouch, 2008), não existe qualquer razão para não reanimar mais uma vez a tradição fundamentada por Kant, Durkheim e Dewey e compreender a educação pública como órgão central da autorreprodução das democracias.

Depois do que foi dito até agora, poderia surgir facilmente a impressão de que, junto com os métodos apropriados de um ensino democrático, também suas matérias estariam dadas de uma vez para sempre e, por conseguinte, permanentemente fora do alcance de toda mudança histórica. Kant, principalmente, deu um forte impulso a essa noção ao vincular a aquisição das formas de autoestima necessárias para o cidadão ao aprendizado gradativo de conteúdos cognitivos atemporalmente válidos, mas também em Durkheim 
(1973, $17^{\mathrm{a}}$ e $18^{\mathrm{a}}$ preleções) se pode identificar a propensão de prescrever determinadas matérias a todos os processos da educação cooperativa como componentes fixos. Só John Dewey contradiz, em seus escritos pedagógicos, a tendência assim esboçada ao salientar repetidas vezes com grande sobriedade que, junto com os respectivos desafios da solução de problemas públicos, os conteúdos materiais do ensino também precisam mudar. Embora também ele parta, como seu companheiro de armas Durkheim, de uma imprescindível hierarquização das disciplinas dos conhecimentos a serem transmitidos em seu caso, surpreendentemente, a geografia e a história ocupam, de modo complementar, o topo da lista (Dewey, 1993, cap. 16) - o que, em cada caso, precisa ser aprendido nessas disciplinas por meio de uma atuação conjunta e cooperativa se mede para ele, única e exclusivamente, pelas tarefas historicamente cambiantes da formação da vontade democrática (ibid., p. 254ss). Não gostaria de terminar minha palestra sem ao menos mencionar brevemente, no espírito de Dewey, os dois desafios históricos que deveriam se refletir sobretudo nas matérias do ensino por causa de suas consequências para a convivência democrática. Ao se considerar as duas problemáticas mais atentamente, deve ficar evidente que elas não podem ser tratadas adequadamente sendo empurradas para uma disciplina avulsa, mas tornam necessária uma cotematização material em quase todo o cânone de disciplinas de nossas escolas.

Para qualquer contemporâneo atento não deveria haver dúvida, atualmente, que a revolução digital da comunicação transformará de modo duradouro não só as formas da formação e manutenção de relações privadas, mas também os caminhos da formação da vontade política. Com a internet, que coloca o indivíduo em condições de ampliar os limites espaciais de suas interações e de acelerá-las, estão surgindo hoje, em ritmo crescente, muitas esferas públicas na rede, cujas fronteiras externas e temas estão em fluxo constante (Honneth, 2011, p. 560-567). Certamente é tarefa do ensino escolar preparar técnica e socialmente os alunos para o uso dessa nova mídia, mas o enfrentamento conjunto de suas consequências históricas nem de longe deve se esgotar nisso. Parece-me, além disso, necessário averiguar em conjunto, na verificação experimental do surgimento de temas e conhecimentos digitalmente disseminados, onde se encontram, além dos potenciais, também os limites e as ameaças da nova mídia. ${ }^{9}$ Em tais reconstruções exemplares, em que, por exemplo, poder-se-iam examinar detidamente a gênese e a qualidade de determinados verbetes da Wikipédia, as diversas disciplinas escolares

\footnotetext{
9 Reflexões nessa direção, retomando John Dewey, são feitas por Richard S. Croft (1993-1994).
} 
teriam de trabalhar em estreita cooperação, porque, além do conhecimento puramente técnico e econômico, também se fariam necessários conhecimentos nas respectivas áreas temáticas. Mas esse único exemplo serve aqui para representar a ideia muito mais geral de que seria importante hoje, em nossas escolas, aprender, junto com o manejo da internet, também suas leis de produção e formas de atuação. As alunos e os alunos deveriam ser preparados, por meio da utilização cooperativa do computador - portanto, inteiramente de acordo com o que preconizava Dewey -, a fazer uso mais tarde, de maneira autônoma, dos novos instrumentos da formação da vontade política.

Se a revolução digital representa o primeiro dos dois desafios diante dos quais se encontra atualmente a esfera pública democrática, a crescente heterogeneidade da população nos países ocidentais representa o segundo deles (cf. Honneth, 2011, p. 535-539). Assim como em relação à nova mídia da internet, também com vistas ao multiculturalismo dificilmente alguém haverá de discordar que nas escolas se deve fazer tudo para preparar as pessoas para essas condições modificadas da formação da vontade pública. Mas também neste caso se coloca mais uma vez a pergunta a respeito de quais são os recursos metodológicos e os conteúdos materiais que melhor poderiam dar conta da tarefa necessária. A ideia da educação democrática, que quis lembrar com minha palestra, já tem a resposta para a primeira parte, a parte metodológica dessa pergunta: quanto menos o aluno ou a aluna for visto, no ensino, como um sujeito isolado, produtor de desempenho, portanto quanto mais fortemente ele ou ela for tratado como membro de uma comunidade de aprendizado cooperativo, tanto mais provavelmente devem se estabelecer entre eles formas de comunicação em que diferenças culturais podem ser não apenas aceitas ludicamente, mas compreendidas como oportunidades de enriquecimento mútuo. ${ }^{10}$ Entretanto, com essa referência à força criadora de reconhecimento da educação democrática ainda não está respondida a segunda pergunta parcial a respeito das consequências que devem ser tiradas do crescente multiculturalismo de nossa sociedade para as matérias a serem ensinadas. Gostaria de concluir com a suposição de que nós todos nem podemos ainda nos imaginar adequadamente como devem ser aqueles conteúdos a serem aprendidos em 15 ou 20 anos caso haja uma consideração justa da composição étnica e cultural das séries escolares. Para que esses futuros alunos e alunas se tornem, mais tarde, participantes autônomos de

10 Quanto a isso, cf. Krassimir Stojanov (2006, princ. cap. 4). Quanto à importância de processos de reconhecimento escolares para a ideia de uma democratização da escola, cf. Annelore Prengel (2011, p. 83-94). 
uma esfera pública que, então, será extremamente heterogênea e variegada, eles terão de se apropriar da história, da literatura, da geografia e da maioria das outras disciplinas a partir da mesma perspectiva descentralizada que nós atualmente estamos procurando aprender, lenta e penosamente, nas respectivas disciplinas nas universidades.

\section{Referências}

ALTHUSSER, Louis. Ideologie und ideologische Staatsapparate. In: Louis Althusser. Marxismus und Ideologie. Westberlin: Verlag für das Studium der Arbeiterbewegung), 1973. p. 111-172 [A ideologia e os aparelhos ideológicos de estado, Editorial Presença].

BÖCKENFÖRDE, Ernst-Wolfgang. Freiheit und Recht, Freiheit und Staat. In: ErnstWolfgang Böckenförde. Recht, Staat, Freiheit. Frankfurt am Main: Suhrkamp, 2006. p. $42-57$.

CROFT, Richard S. What is a computer in the classroom? A Deweyan philosophy for technology in education. Journal of Educational Technology Systems, v. 22, n. 4, p. 301-308, 1993-1994.

CROUCH, Colin. Postdemokratie. Frankfurt am Main: Suhrkamp, 2008.

DURKHEIM, Emile. Erziehung, Moral und Gesellschaft. Neuwied am Rhein: Luchterhand, 1973.

DEWEY, John. Demokratie und Erziehung: Eine Einleitung in die philosophische Pädagogik. Weinheim: Beltz, 1993 [Democracia e educação, Companhia Editora Nacional].

DUBET, François. Le déclin de l'institution. Paris: Seuil, 2002.

DUBET, L'égalité et le mérite dans l'école démocratique de masse. L'Année Sociologique, v. 50, n. 2, p. 383-408, 2000.

FORST, Rainer. Kontexte der Gerechtigkeit. Frankfurt am Main: Suhrkamp, 1994 [Contextos da justiça, Boitempo Editorial].

GAGEL, Walter. Geschichte der politischen Bildung in der Bundesrepublik Deutschland 1945-1989/90. 3. ed. Wiesbaden: Leske + Budrich, 2005.

GUTMANN, Amy. Democratic education. 2. ed. Princeton: Princeton University Press, 1999.

HONNETH, Axel. Das Recht der Freiheit: Grundriss einer demokratischen Sittlichkeit. Frankfurt am Main: Suhrkamp, 2011.

KANT, Immanuel. Über Pädagogik. In: Immanuel Kant. Werke in zwölf Bänden. Frankfurt am Main, 1964. v. 12 [Sobre a pedagogia, Edições 70].

OELKERS, Jürgen. John Dewey und die Pädagogik. Weinheim: Beltz, 2009.

PLATON. Politeia. In: PLATON. Werke in acht Bänden. Ed. de Gunther Eigler. 2. ed. Darmstadt: Wissenschaftliche Buchgesellschaft, 1990. v. 4.

PRENGEL, Annelore. Zwischen Heterogenität und Hierarchie in der Bildung: Studien zur Unvollendbarkeit der Demokratie. In: L. Ludwig et al. (Orgs.). Bildung in der Demokratie II. Opladen: Barbara Budrich, 2011, p. 83-94. 
RAVITCH, Diane. Schools we can envy. New York Review of Books, v. 59, n. 4, p. 19-20, 2012.

RAWLS, John. Der Vorrang des Rechten und die Ideen des Guten. In: John Rawls. Die Idee des politischen Liberalismus: Aufsätze 1978-1989. Frankfurt am Main, 1992. p. 364-397 [Liberalismo político, Ática].

RAWLS, John. Eine Theorie der Gerechtigkeit. Frankfurt am Main, 1979 [Uma teoria da justiça, Martins Fontes).

SAHLBERG, Pasi. Finnish lessons: what can the world learn from educational change in Finland? New York: Teachers College Press, 2012.

SCHLEIERMACHER, Friedrich. Über den Beruf des Staates zur Erziehung. In: Friedrich Schleiermacher. Texte zur Pädagogik: Kommentierte Studienausgabe. Ed. de Michael Winkler e Jens Brachmann. Frankfurt am Main: Suhrkamp, 2000. v. 1, p. 272-290.

STOJANOV, Krassimir. Bildung und Anerkennung: Soziale Voraussetzungen von Selbstentwicklung und Welt-Erschliessung. Wiesbaden: Westdeutscher Verlag, 2006.

WALZER, Michael. Sphären der Gerechtigkeit. Frankfurt am Main: Suhrkamp, 1992 [Esferas da justiça, Martins Fontes].

Autor correspondente:

Axel Honneth

Grüneburgplatz 1 - IG 2.515

60629 Frankfurt am Main - Alemanha

Recebido em: 14 jun. 2012

Aprovado em: 15 out. 2012 